NBER WORKING PAPER SERIES

\author{
EFFECTS OF ALCOHOLIC BEVERAGE \\ PRICES AND LEGAL DRINKING AGES \\ ON YOUTH ALCOHOL USE
}

\author{
Douglas Coate \\ Michael Grossman
}

Working Paper No. 1852
NATIONAL BUREAU OF ECONOMIC RESEARCH 1050 Massachusetts Avenue
Cambridge, MA 02138
March 1986

The research reported here is part of the NBER's research program in Health Economics. Any opinions expressed are those of the authors and not those of the National Bureau of Economic Research. 
NBER Working Paper \#1852

March 1986

\title{
Effects of Alcoholic Beverage Prices and Legal Drinking Ages on Youth Alcohol Use
}

\begin{abstract}
Based on an analysis of the second National Health and Nutrition Examination Survey, conducted between 1976 and 1980 , we find that the frequency of the consumption of beer, the most popular alcoholic beverage among youths, is inversely related to the real price of beer and to the minimum legal age for its purchase and consumption. The negative price and legal drinking age effects are by no means limited to reductions in the fraction of youths who consume beer infrequently (less than once a week). Instead, the fractions of youths who consume beer fairly frequently (1-3 times a week) and frequent1y (4-7 times a week) fall more in absolute or percentage terms than the fraction of infrequent drinkers when price or the drinking age rises. These are striking findings because frequent and fairly frequent drinkers are likely to be responsible for a large percentage of youth motor vehicle accidents and deaths. Simulations suggest that, if reductions in youth alcohol use and abuse are desired, both a uniform drinking age of 21 and an increase in the Federal excise tax rate on beer are effective policies to accomplish this goal. They also suggest that the tax policy may be more potent than the drinking age policy.

Douglas Coate Department of Economics Rutgers University Newark, New Jersey 07102 (201) 648-5259

Michae1 Grossman Department of Economics City University of New York Graduate School 33 W. 42nd Street New York, New York 10036 (212) 790-4411
\end{abstract}


EFFECTS OF ALCOHOLIC BEVERAGE PRICES AND

LEGAL DRINKING AGES ON YOUTH ALCOHOL USE

Douglas Coate and Michael Grossman*

\section{Introduction and Background}

Since the mId 1970s, the Federal government of the United States and various state and local governments have been involved in a campaign to reduce deaths from motor vehicle accidents by discouraging alcohol abuse. One major element of this campaign has been the upward trend in state minimum legal ages for the purchase and consumption of alcoholic beverages that began with the increase in the legal drinking age in Minnesota from 18 to 19 years of age in 1976. An additional 27 states had increased legal drinking ages by the time of the Federal Uniform Drinking Act of Ju1y 1984 . This legislation allows the Federal government, through its control of Federal highway funds, to intercede in a legislative area traditionally reserved for states. Five percent of a state's Federal highway construction fund allocation for the fiscal year 1987 will be withheld if the minimum legal drinking age is below 21 years on October 1, 1986, and 10 percent will be withheld from the 1988 fiscal year allocation if its drinking age is below 21 on October 1, 1987. To date, 14 states have passed laws complying with the act, and a total of 37 states now have a minimum drinking age of $21 .^{1}$ A second major element of the antidrinking campaign is reflected by more severe penalties for conviction of drunken driving, the allocation of additional resources to apprehend drunk drivers, and an easing in the standards required for conviction. 
One policy that has been virtually ignored by the Federal and state governments in the antidrinking campaign is increased taxation of alcoholic beverages which, by raising prices, would lower alcoholic beverage consumption. Instead, the Federal excise tax rates on liquor (distilled spirits), beer, and wine remained constant in nominal terms between November 1, 1951 and the end of fiscal 1985. During this period the Federal government taxed liquor at the rate of $\$ 10.50$ per proof gallon (one gallon of 100 proof 1iquor, which is the equivalent of 50 percent alcohol by volume), beer at the rate of $\$ .29$ per gallon (approximately 4.5 percent alcohol by volume), and wine at the rate of $\$ .17$ per gallon (between 11.6 percent and 21 percent alcohol by volume). ${ }^{2}$

Partly as a result of the stability of the Federal excise taxes and the modest increases in state and local excise taxes, the real price of alcoho1ic beverages (the nominal price divided by the Consumer Price Index) has declined substantially over time. Between 1960 and 1980 , the real price of 1iquor fell by 48 percent; the real price of beer fell by 27 percent; and the real price of wine fell by 20 percent (Cook 1981). While 29 states raised the legal drinking age from 1976 through 1984, rea1 alcoholic beverage prices continued to fall: 27 percent for liquor, 12 percent for beer, and 19 percent for wine (Bureau of Labor Statistics various years). Thus, as argued by Cook and Tauchen (1982), if alcohol abuse is sensitive to price, a government policy of declining real excise tax levels actually may be exacerbating this problem.

A primary purpose of this paper is to investigate the sensitivity of alcoholic beverage consumption, particularly excessive consumption, to price among 16 through 21 year olds in the U.S. Thus, we provide evidence 
for this important age group on the extent to which declining real alcoholic beverage excise taxes have contributed to increases in youth drinking and on the extent to which increases in real alcoholic beverage excise taxes can serve as a potent instrument in the antidrinking campaign. We also examine the effect of an increase in the legal drinking age on youth alcohol use. Our empirical research is based on the second National Health and Nutrition Examination Survey (NHANES II), conducted by the National Center for Health Statistics (NCHS) between February 1976 and February 1980. It capitalizes on substantial differences in legal drinking ages among states in the period of NHANES II and on substantial differences in the prices of alcoholic beverages among states due primarily to differences in state excise tax rates on these beverages.

We focus on teenagers and young adults in the context of the antidrinking campaign because motor vehicle accident mortality is the leading cause of death of persons under the age of 35 , and the National Highway Traffic Safety Administration (1983) estimates that alcohol is involved in over half of these fatal accidents. In 1979 persons under the age of 25 accounted for 22 percent of all licensed drivers but 38 percent of all drivers involved in fatal accidents (National Highway Traffic Safety Administration 1983). These figures are even more dramatic than they appear because members of the young driver group do not drive nearly as much as older drivers (Voas and Moulden 1980). We also focus on youths because alcohol abuse in adolescence appears to be associated with alcohol abuse in adult life (for example, Blane and Hewitt 1977; Rachal et al. 1980). Thus, policies to prevent the onset of this behavior by adolescents 
might be the most effective means to reduce it in all segments of the popu1ation.

Research on the responsiveness of youth alcohol use to alcoholic beverage prices is particularly timely in light of proposals to correct the erosion in the real value of the Federal excise tax rates on all forms of alcoholic beverages since 1951 and to prevent future erosion by indexing tax rates to the rate of inflation or by converting to an ad valorem alcoholic beverage excise tax system (for example, Moore and Gerstein 1981; Luks 1983; Cook 1984; Harris 1984; Becker 1985; Jacobson and Albion 1985). 3 Moreover, although beer is the drink of choice among youths who drink alcoholic beverages (see Section II), the alcohol in liquor is taxed three times as heavily as the alcohol in beer. This has led to suggestions to equalize the tax rates on the alcohol in all forms of alcoholic beverages by raising the tax on beer (for example, Harris 1984; Jacobson and Albion 1985). 4 Research on the sensitivity of youth alcohol use to legal drinking ages is also valuable given the adverse reaction to Federal uniform drinking legislation, ${ }^{5}$ its scheduled expiration at the end of fiscal 1988, and volatility in state minimum drinking ages in the 1970 s and 1980 s. Aside from our study with Arluck (Grossman, Coate, and Arluck forthcoming) described below, there is no research on the price sensitivity of youth alcohol use and no investigations of the long-run impacts of differences in legal drinking ages in recent nationally representative samples. Statistically significant short-run increases in alcohol consumption by youths have been reported in selected states or provinces of Canada that lowered their legal drinking age in the early 1970s, and significant short-run reductions in consumption have been reported in selected states 
that raised their legal drinking age in the late 1970s or early 1980s (for example, Smart and Goodstadt 1977; Wagenaar 1983; Williams and Lillis 1985).6 Grossman, Coate, and Arluck (forthcoming) find that the incidence of heavy drinking and frequent drinking by youths falls as alcoholic beverage prices or legal drinking ages rise. These results are based on the first National Health and Nutrition Examination Survey (NHANES I), conducted by NCHS between May 1971 and June 1974, and pertain to youths ages 16 through 21 who reside in large metropolitan areas.

Studies that use time series or state cross sections to estimate price elasticities of alcoholic beverages (for example Ornstein 1980; Ornstein and Hanssens 1985) employ per capita consumption by all age groups as the dependent variable. Therefore, the estimated price elasticities primarily reflect adult drinking behavior and cannot be used to predict how youths would respond to excise tax and price changes. As pointed out above, however, it is especially important to focus on youths in the context of the antidrinking campaign.

It should be noted that, even if adult price elasticities are relatively small (inelastic) in absolute value, this need not be the case for youth price elasticities. Given the habitual nature of alcohol abuse, adult users, who almost always will have been users for longer periods of time than youths, may be much less sensitive to price than youths. In addition, the fraction of his disposable income that a youthful drinker spends on alcohol probably exceeds the corresponding fraction of an adult drinker. It is well known that the uncompensated (money income-constant) price elasticity of a good rises as the fraction of income spent on that good rises. Finally, bandwagon or peer effects are much more important in 
the case of youth drinking than in the case of adult drinking. That is, youths are more likely to drink if their peers also drink (for example Blane and Hewitt 1977; Racha1 et a1. 1980). As shown by Leibenstein (1950) and by Lewit, Coate, and Grossman (1981), the presence of bandwagon or peer effects increases the price elasticity of demand. ${ }^{7}$

\section{Methodology}

\section{A. Data and Subsample Selection}

To examine the effects of alcohol prices and legal drinking ages on youth alcohol use, we use the second National Health and Nutrition Examination Survey (NHANES II) to estimate demand functions for alcohol consumption by youths. NHANES II is a national probability sample of the civilian, noninstitutionalized population of the U.S., with some oversampling of low-income persons, preschool children, and the elderly. The survey was conducted by the National Center for Health Statistics (NCHS) between February 1976 and February 1980 and contains approximately 21,000 persons between the ages of 6 months and 74 years. These persons were selected from 64 primary sampling units, which consist of one or more counties. Each person in the survey was given a detailed physical examination. A variety of information on medical and health histories, family socioeconomic characteristics, and diet patterns also was obtained. Data on alcohol use for the past three months were collected for persons ages 12 through 74. These data were acquired on the date on which the physical examination was given as one component of a food frequency interview. 8

We have limited our demand function estimates to 16 through 21 year olds because of our interest in the sensitivity of alcohol consumption of older 
youth to price and to legal drinking age. Youths below the age of 16 are excluded from the demand functions because they cannot drive legally in most states. Youths ages 16 and 17 are 11 legal drinkers in all states, but they are included in the demand functions because it is likely to be easier (less costly) for them to obtain alcoholic beverages in a state with a legal drinking age of 18 than in one with a higher legal drinking age (Cook and Tauchen 1984). Twenty-one year olds are legal drinkers in all states, but they are not excluded from the demand functions because 21 year olds in states with a legal drinking age of 18 will have been legal drinkers for a longer period of time than simllar youths in states with a legal drinking age of 19,20 , or 21 . This may have an impact on their consumption of alcoholic beverages. Although the 16 through 21 age range is somewhat arbitrary, demand functions estimated with youths of slightly different ages (15 through 20 or 16 through 20 ) yield results that are very similar to those presented in Section III.

Alcoholic beverages prices and legal drinking ages have been added to the NHANES II survey based on a given youth's place of residence (primary sampling unit) from sources indicated in Section II.C. Since beer prices for the state of Hawail were not available and since beer is the drink of choice among youths who consume alcoholic beverages (see Section II.B), youths residing in Honolulu, Hawail were excluded. After deleting observations with missing data, we obtained a final sample of 1,761 youths ages 16 through 21 living in 63 of the 64 NHANES II primary sampling units. 9

\section{B. Measurement of Alcohol Use}

NHANES II alcohol use measures for the final sample of 1,761 youths are 
summarized by the percentage distributions of beverage-specific drinking frequencies in the past three months in Panel A of Table 1 . These measures pertain to the number of drinking occasions per week in the past three months; information on the number of drinks consumed in total or on a typical drinking occasion was not obtained. The figures in Table 1 highlight the popularity of beer among teenagers and young adults. Approximately 57 percent of all youths drank beer in the past three months, while only 39 percent drank liquor and only 32 percent drank wine. Moreover, 11 percent of youths drank beer 4-7 times a week, while less than 1 percent drank liquor or wine that often.

The beverage-specific number of drinking occasions in the past three months is a categorical variable in NHANES II, and the four categories shown in Table 1 (4-7 times a week, 1-3 times a week, less than once a week, and never) are employed as outcome measures in demand functions estimated by multivariate techniques described in Section II.D. ${ }^{10}$ Here it is important to note that the use of a categorical variable allows us to examine the determinants of beverage-specific drinking participation and infrequent, fairly frequent, and frequent participation simultaneously. It also permits the impacts of prices and legal drinking ages on these outcomes to differ. In addition, if more alcohol is consumed per drinking occasion as the number of occasions rises, true consumption would not be linearly related to a continuous drinking frequency measure. To take account of this nonlinearity, a categorical variable would be preferable to a continuous one even if the latter were available.

The number of drinking occasions per week is closely related to, and in a majority of cases probably coincides with, the number of drinking days 
Table 1

Variables Employed In Emplrical Analyais

Panel A: Percentage Distributions of Beverage-Specific Drinking Frequencles In Past Three Monthsa

\begin{tabular}{lcccc}
\hline & \multicolumn{4}{c}{ Outcome Category } \\
\cline { 2 - 5 } Beverage & $\begin{array}{c}4-7 \text { times } \\
\text { aweek }\end{array}$ & $\begin{array}{c}1-3 \text { t1mes } \\
\text { a week }\end{array}$ & $\begin{array}{c}\text { less than } \\
\text { once } \\
\text { a week }\end{array}$ & never \\
\hline Beer & 11.07 & 27.43 & 18.57 & 42.93 \\
L1quor & .85 & 13.57 & 24.48 & 61.10 \\
W1ne & .85 & 9.20 & 22.37 & 67.58 \\
\hline
\end{tabular}

Panel B: Definttions, Means, and Standard Deviations of Independent Varlables

\begin{tabular}{|c|c|}
\hline Varlable Name & Definition \\
\hline $\begin{array}{l}\text { Real price of beer } \\
(1967 \text { dollars })\end{array}$ & $\begin{array}{l}\text { Price of a package of } 91 x-12 \text { ounce cans of } \\
\text { a leading brand of beer d1v1ded by Consumer } \\
\text { Price Index, 1967-1 (mean-1.027, s.d.=.116) }\end{array}$ \\
\hline $\begin{array}{l}\text { Real price of 11quor } \\
\text { (1967 dollars) }\end{array}$ & $\begin{array}{l}\text { Price of Seagram'a 7-Crown, } 80 \text { proof ( } 40 \\
\text { percent alcohol), fifth s1ze bottle (four- } \\
\text { fiftho of a quart), divided by Congumer } \\
\text { Price Index, 1967-1 (mean-2.941, s.d.-.309) }\end{array}$ \\
\hline $\begin{array}{l}\text { Beer legal drinking age } \\
\text { (monche) }\end{array}$ & $\begin{array}{l}\text { Mintium legal age for purchase and con- } \\
\text { eumption of beer, alcohol1c content } 3.2 \\
\text { percent or less (mean-228.572, s.d.-16.092) }\end{array}$ \\
\hline $\begin{array}{l}\text { Liquor legal drinking age } \\
\text { (monthe) }\end{array}$ & $\begin{array}{l}\text { Mintmum legal age for purchase and con- } \\
\text { oumption of l1quor (wean=234.835, e.d. }=17.651 \text { ) }\end{array}$ \\
\hline Border age & 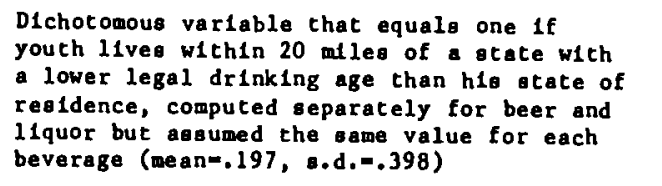 \\
\hline Mormon & $\begin{array}{l}\text { Percentage of population who are Mormong } \\
\text { in youth's primary sampling unit (mean=l.585, } \\
\text { B.d.=8.323) }\end{array}$ \\
\hline Southern Baptist & $\begin{array}{l}\text { Percentage of population who are Southern } \\
\text { Baptiots 1n youth's primary oampling unit } \\
\text { (mean=7.955, o.d.-13.179) }\end{array}$ \\
\hline Catholic & $\begin{array}{l}\text { Percentage of population who are Catholica } \\
\text { In youth's primary sampling unic } \\
\text { (mean-19.161, s.d.-15.708) }\end{array}$ \\
\hline Protestant & $\begin{array}{l}\text { Percentage of population who are } \\
\text { Protestante in youth's primary sampling } \\
\text { unit, excludes Southern Baptiats and } \\
\text { Mormong (mean-20.465, B.d.-8.389) }\end{array}$ \\
\hline
\end{tabular}

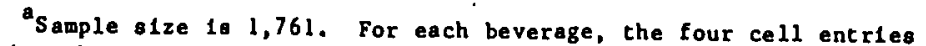
give the percentage of all youths in each outcome cacegory.

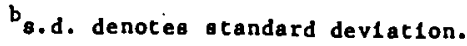


per week. Under this interpretation, the most frequent drinking category identifies youths who consumed alcohol at least every other day in the past three months. Given the age cohort studied here, this is a very reasonable indicator of frequent consumption.

Information on alcohol consumption was obtained directly from youths in NHANES II. Parents were not present during the interviews with the youths and were not informed about the alcohol responses of their children. Nevertheless there is a possibility that youths may report their alcohol use with error. If any such response error is uncorrelated with the independent variables in the demand function for alcohol, coefficients will be unbiased, although their standard errors will be inflated. In this case the existence of response error essentially presents no problem for the statistical analysis. Response error only becomes a problem if it is systematic or correlated with some or all of the variables in the demand functions.

The validity of the NHANES II alcohol measures is underscored by referring to the related problem of the measurement of cigarette smoking by adolescents. Williams and Giles (1984) have reviewed the 11terature on self-reported smoking behavior of adolescents and have concluded "...that teenagers probably do report 'truthfully' about their smoking behavior when anonymous questionnaires are used (p.297)." An additional consideration is that the drinking questions were included as a small part of a much larger survey that was focused on very different issues. Gordon and Kannel (1983) argue that this improves the quality of reports of alcohol consumption. To be sure, it is possible that heavy consumers of alcoholic beverages are more likely to underreport their consumption than other persons 
(Midantk 1982; Pollch 1982). If heavy users are more likely to be found In areas with low prices or low legal drinking ages, estimates of the demand parameters of these variables are biased toward zero. This is another reason for the use of a categorical rather than a continuous drinking measure. In particular, the former does not assume a linear relatlonship between true and reported consumption. Moreover, youths are unl1kely to be found in one of the four outcome categories used here rather than another due to reporting error.

\section{Measurement of Independent Variables}

Panel B of Table 1 contalns definftions, means, and standard deviations of the key Independent variables in the demand functions. In addition to the variables listed In Panel B, all demand functions include as regressors the youth's age in months on the date of his or her NHANES II examination, a dichotomous variable that identifles blacks, a dichotomous variable that Identifles females, and real family income (money family income divided by the Consumer Price Index). We do not present or discuss the effects of these variables on alcohol use in Section III. But it should be realized that all estimated price and legal drinking age effects control for (hold constant) the effects of these variables. We use a relatively sparse set of Independent variables because Arluck (In progress) finds that the coefficients of interest in NHANES I demand functions are not sensitive to the Inclusion of additional family background and youth characteristics. They also do not change much when state-specific measures of the avallability and regulation of alcohol are added to the set of Independent variables. 11 The minfmum legal ages in months for the purchase of beer (alcoholic 
content 3.2 percent or less by weight) and liquor were taken from Wagenaar's (1981/82) extremely painstaking and definitive compilation of these ages for every state for the years 1970 through $19810^{12}$ Each NHANES II youth is assigned beverage-specific legal drinking ages in his state of residence as of the mid-month of the three-month period culminating on the date of his examination. In principle this algorithm takes account of the upward trend in state legal drinking ages during the period of the NHANES II examinations. In fact only two NHANES II primary sampling units -Dakota, Minnesota and Hennepin, Minnesota -- are in a state that raised its legal drinking age during a three-month period culminating on the date of the examination or before that period. All other states that raised their legal drinking age did so after the NHANES II examinations in those states were completed. ${ }^{13}$

Youths who reside in a state with a high legal drinking age may be able to purchase alcohol in a border state with a lower legal drinking age. To deal with this phenomenon, we created a dichotomous variable that equals one for youths who live within 20 mtles of a state with a lower legal drinking age than the one in their state of residence. With the own-state legal drinking age held constant, the coefficient of the border age variable in the demand functions should be positive. 14

The beer price variable pertains to the transactions price of a single leading brand of medium priced, nationally sold beer. The specific brand is confidential. Prices are reported in two unidentified major markets in each state (one in the cases of Rhode Island and the District of Columbia) In January and July of 1976, 1977, and 1978 and in January of 1979. The data were obtained by Stanley Ornstein (see Ornstein and Hanssens 1985) and 
kindly made available to us.

Monthly prices for each state from January 1976 through January 1979 were obtained by linear interpolation of state-specific price series computed by averaging the two prices for each state at a moment in time. Monthly prices for the period February 1979 through January 1980 were predicted from a regression of the state price on the state excise tax rate, time (a continuous variable), and dichotomous variables for all contiguous states except one. ${ }^{15}$ The beer price of the mid-month in the three month period for which alcoholic beverage consumption was reported was then assigned to each subject. ${ }^{16}$ To take account of trends in the prices of other goods during the four-year period of NHANES II, the monthly beer price is divided by the annual Consumer Price Index (CPI, 1967=1) to obtain the real or relative price of beer. ${ }^{17}$

The real price of liquor is given by the price of Seagram's 7-Crown (a blended whiskey) divided by the CPI. This price is selected because Seagram's 7-Crown was the leading brand of liquor in the U.S. during the period of NHANES II, and its price commonly is used as a standard in the liquor industry. It was obtained from the annual survey of the retail prices of eight leading brands of distilled spirits in each state conducted by the Distilled Spirits Council of the United States (DISCUS various years) and kindly made available to us by Gary Marsha11. 18

There were no data available on wine prices by state for the period of NHANES II. As a result wine demand functions are not presented in the following section.

To take account of the potential role of "drinking sentiment" in the endogenous determination of alcoholic beverage prices, legal drinking ages, 
and alcohol consumption, the percentages of the population in a youth's primary sampling unit who are Mormons, Southern Baptists, Catholics, and Protestants (excluding Southern Baptists and Mormons) are included in some specifications of the demand functions. Drinking sentiment refers to cultural and taste variables that may either encourage or discourage alcohol consumption. For example, antidrinking sentiment should be relatively widespread in states where religious groups that oppose the use of alcohol, such as Mormons and Southern Baptists, are prevalent. These states may enact high alcoholic beverage excise tax rates as part of the political process. In this situation, the price coefficients that emerge from demand functions that omit drinking sentiment overstate in absolute value the true parameters. On the other hand, states in which prodrinking sentiment is prevalent (antidrinking sentiment is weak) and alcohol consumption is large may enact high excise tax rates because the taxation of alcoholic beverages is an attractive source of revenue. In this case, the price effects are understated if drinking sentiment is excluded from the demand functions. 19

The preceding issue is illuminated with reference to an econometric model of the determinants of beer consumption both at the aggregate (state or county) level and at the individual level (available upon request). The price of beer, the legal drinking age, drinking sentiment, and beer consumption are treated as endogenous. The model is recursive rather than simultaneous, but the disturbance terms in the price and demand equations, for example, are correlated. This is because drinking sentiment is not observed. Instead, it must be replace by a vector of observable variables, whose elements in the state model include the state-specific equivalents of the religion measures in Table 2 and a disturbance term. 
Blases arise if the demand function is estimated by ordinary least squares because the disturbance terms in that equation and the price equation share a common element: the unobserved component of drinking sentiment. It is shown, however, that the importance of omitted variables bias is greatly reduced when individual demand functions are estimated with drinking sentiment omitted. This is because an individual consumer's beer consumption depends on his drinking sentiment, while the tax on beer or its price depends on the average value of drinking sentiment in the relevant market area. Therefore, the correlation between price (a state or county variable) and drinking sentiment is much weaker in micro data than in aggregate data.

The above conclusion is important because no measures of an individual's religious preference are available in NHANES II, and two-stage least squares estimation of demand functions with price treated as endogenous is not feasible. Some demand functions are obtained with the four primary sample-specific religion variables listed in Table 2. These results should, however, be interpreted with caution because the price of beer or liquor is specific to the state rather than to the primary sampling unit. Given errors of measurement in price and correlations between true price and the religion variables, price coefficients are biased toward zero and religion coefficients are biased away from zero. Therefore, we wish to reemphasize that price effects are not necessarily overstated in absolute value when drinking sentiment is excluded from the demand functions.

The religion variables pertain to 1980 and were taken from a survey conducted by the National Council of the Churches of Christ and the Glenmary Research Center (see Quinn et al. 1982). Jews are included with 
non-church members in the omitted category because the size of the Jewish population was significantly underestimated in the survey. The religion measures pertaln to the youth's primary sampling unit of residence rather than to his state of residence because the former are better predictors of the youth's actual religion.

Although youths are more likely to drink if their peers also drink, it is inappropriate to include peers' consumption of alcohol in the demand functions. This is because peer behavior is an endogenous rather than an exogenous variable in a more broadly defined model of drinking. That is, this behavior is determined by such a model rather than outside it. For instance, suppose that one is evaluating a policy to curtail youth drinking by raising the Federal excise tax rate on beer. An increase in the tax would raise the price of beer paid by youths and their peers, which would discourage consumption by both groups. Therefore, in evaluating the impact of such a policy, peers' beer consumption should not be held constant (included in the demand equation).

\section{Estimation Techniques}

The beverage-specific frequency of drinking in the past three months consists of four outcome categories (see Table 1). Therefore, multinomial logit equations are fitted by the method of maximum likelihood. In the case of beer, let $\pi_{i 1}, \pi_{12}, \pi_{i 3}$, and $\pi_{i 4}$ be the probabilities that the $1^{\text {th }}$ youth consumes beer 4-7 times a week, 1-3 times a week, less than once

a week and never, respectively. The probability of the $k^{\text {th }}$ outcome

$$
\begin{aligned}
& \left(\pi_{i k}, k=1,2,3\right) \text { is } \\
& \pi_{i k}=\pi_{i 4} \exp \left(\alpha_{k}+\sum_{t=1}^{n} \beta_{k t} x_{i t}\right),
\end{aligned}
$$


where $x_{i t}$ is the value of the $t^{\text {th }}$ independent variable for the $1^{\text {th }}$ youth. The logarithm of the odds of category $k$ relative to category 4 is

$$
\ln \left(\pi_{1 k} / \pi_{14}\right)=\alpha_{k}+\sum_{t} \beta_{k t} x_{1 t}
$$

The logit coefficient $\beta_{k t}$ shows the percentage change in the odds of category $i$ relative to no beer participation for a one unit change in $x_{1 t^{*}}$ The marginal effect of $x_{1 t}$ on $\pi_{1 k}$ is

$$
\left(\partial \pi_{i k} / \partial x_{k t}\right)=\pi_{i k} \beta_{k t}-\pi_{i k} \sum_{k=1}^{3} \pi_{i k} \beta_{k t} \cdot
$$

Multinomia1 logit estimation methods are discussed in detail by Maddala (1983). Here it is important to emphasize several features of our estimates. The measures of drinking frequency are ordered categorical variables, but we do not use the ordered logit model (for example, Maddala 1983). This is because that model does not allow for nonlinear and possibly nonmonotonic effects of the independent variables on the outcomes at issue.

Since the beer frequency equation, for example, contains non-beer drinkers (the omitted category), it gives an estimate of the effect of each independent variable on the probability of no beer participation. ${ }^{20}$ We do not model beer consumption as a two-stage process in which youths first determine whether they will drink beer and then determine the frequency of beer consumption given participation. In the two-stage model non-beer participants would be excluded from the equation for frequency. We do not use this model because it is appropriate only when the determinants of participation differ from those of frequency (McFadden 1973). This condition is not satisfied in our research. 21

\section{Results}

Table 2 contains maximum likelihood estimates of multinomial logit beer 


\section{Table 2}

Maximum Likelihood Estimates of Multinomial Logit Beer Frequency Equations ${ }^{a}$

\begin{tabular}{cccc} 
& \multicolumn{3}{c}{ Outcome Category } \\
\cline { 2 - 4 } $\begin{array}{c}\text { Independent } \\
\text { Variable }\end{array}$ & $\begin{array}{c}4-7 \text { times } \\
\text { a week }\end{array}$ & $\begin{array}{c}1-3 \text { times } \\
\text { a week }\end{array}$ & $\begin{array}{c}\text { once } \\
\text { a week }\end{array}$ \\
\hline
\end{tabular}

Panel A: Religion Variables Excluded

$\begin{array}{lrrr}\text { Real price of beer } & -1.790 & -1.209 & -.587 \\ \text { Beer legal drinking age } & (-2.12) & (-2.19) & (-1.01) \\ \text { Border age } & -.024 & -.015 & -.008 \\ & (-3.69) & (-3.24) & (-1.62) \\ & .196 & .366 & .279 \\ \text { Chi-square } & (.74) & (2.01) & (1.43) \\ \end{array}$

Panel B: Religion Variables Included

Real price of beer

Beer legal drinking age

Border age

Mormon

Southern Baptist

Catholic

Protestant

Chi-square

$\begin{array}{rrr}-1.028 & -.987 & -.714 \\ (-1.12) & (-1.57) & (-1.07) \\ -.019 & -.008 & -.001 \\ (-2.63) & (-1.68) & (-.28) \\ -.079 & .994 & .008 \\ (-.027) & (.51) & (.04) \\ -.026 & -.010 & -.019 \\ (-1.38) & (-1.16) & (-1.58) \\ -.031 & -.021 & -.014 \\ (-3.09) & (-3.23) & (-1.98) \\ .013 & .015 & .012 \\ (1.48) & (2.47) & (1.79) \\ .028 & .035 & .039 \\ (1.91) & (3.44) & (3.62)\end{array}$

464.18

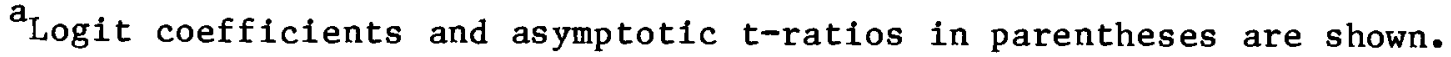
The critical asymptotic t-ratios at the 5 percent level are 1.64 for a onetailed test and 1.96 for a two-tailed test. The chi-square associated with each equation is significant at the 1 percent level. Each equation includes three intercepts and the following additional independent variables: age of youth in months, race of youth, sex of youth, and real family income. 
frequency equations. Logit coefficients and their asymptotic t-ratios are shown. 22 An equation that excludes the four religion measures is presented In Panel $A$ of the table, while an equation that includes them is presented In Panel B. In the discussion of these results, youths who drink beer 4-7 times a week are termed frequent drinkers; those who drink 1-3 times a week are termed fairly frequent drinkers; and those who drink less than once a week are termed infrequent drinkers.

In the beer frequency equation in Panel $A$, the logit coefficients of the real price of beer and the legal drinking age all are negative and are statistically significant at the 5 percent level of significance or better except in the infrequent drinking category. ${ }^{23}$ The border legal age coefficients have the appropriate positive signs, but only the coefficient pertaining to fairly frequent drinking is significant.

There is a perfect rank correlation between the absolute values of the price and legal drinking age coefficients and the number of drinking occasions represented by each outcome category. That is, the logit coefficient of price in the frequent drinking category exceeds the corresponding coefficient in the fairly frequent category. In turn the latter exceeds the logit coefficient of price in the infrequent category. In general this guarantees that an increase in price lowers the probabilities of frequent and fairly frequent drinking. Indeed the price elasticities of the probabilities of frequent and falrly frequent beer consumption are substantial: -1.18 and -.59 , respectively. The price elasticity of the probability of Infrequent drinking is positive and very small (.05), which indicates that the probability of Infrequent drinking rises (but by a smaller percentage than that of nonparticipation) as the real price of beer rises. The posi- 
tive price elasticity of the probability of nonparticipation of .65 is relatively large. 24

The price and legal drinking age effects retain their negative signs and relative rankings when the religion variables are included as regressors (see Panel B of Table 2), but the significant coefficients in the equation in Panel $\mathrm{A}$ are reduced in absolute value. In percentage terms these reductions range from 47 percent for the legal drinking age coefficlent associated with the fairly frequent outcome category to 18 percent for the price coefficient in the same category. The two significant legal drinking age coefficients in Panel A retain their significance in Panel $B$. The price coefficients, however, lose their significance at the 5 percent level, although the t-ratio associated with each coefficient exceeds one in absolute value. The price elasticities are still relatively large: -.53 for the probability of frequent drinking, -.48 for the probability of fairly frequent drinking, -.20 for the probability of infrequent drinking, and .53 for the probability of no drinking. For all practical purposes, there are no border age effects when the religion variables are held constant. The frequency of beer consumption is negatively related to the percentage of Mormons or Southern Baptists in the primary sampling unit, while it is positively related to the percentage of Catholics or Protestants.

Recall from Section III.C that the price and legal drinking age coefficients are likely to be conservative lower-bound estimates of the true parameters with the religion variables included in the demand equations. Also, the corresponding coefficients obtained without controlling for religion are not necessarily upper-bound estimates of the true parameters. In 
light of these considerations, the findings that the real beer price coefficients retain their signs and relative rankings and the beer legal drinking age coefficients retain their signs, rankings, and statistical significance are impressive and important.

Fewer negative and significant price and legal drinking age effects emerge from the demand functions for liquor (not shown) than from the demand functions for beer. Moreover, the negative liquor price elasticities are smaller in absolute value than the corresponding beer price elasticities. For these reasons and because beer is the most popular alcoholic beverage among youths, we focus on the frequency of beer consumption in the remainder of this paper.

In logit equations not shown, the real price of liquor was included in the demand functions for beer. No evidence of substitution between beer and liquor was revealed by these equations. In most cases the cross price effect was negative (suggesting complementarity) but not significant. This finding is probably not an artifact of multicollinearity; the simple correlation coefficient between the price of beer and liquor is positive but not substantial $(r=.19)$.

To evaluate the potential impacts of the Federal excise tax and legal drinking age policy initiatives discussed in Section I, we simulate their effects on the frequency of beer consumption by youths. Specifically, first we compute the "actual" percentage distribution of the frequency of beer consumption (4-7 times a week, 1-3 times a week, 1ess than once a week, and never) by predicting the four outcome probabilities $\left(\pi_{1 k}\right)$ for each youth based on the logit coefficients and the actual value of each independent variable $\left(x_{1 t}\right)$ for that youth [see equation ( 1 ) and the second 
equation in note 20]. Then we average each of the four outcome probabilities over all youths. Next we vary one or more of the independent variables by a certain amount, recompute each $\pi_{1 k}$, and average a given probability over all youths. This gives a "new" percentage distribution.

The legal drinking age policy pertains to a uniform minimum age for the purchase of beer of 21 in all states. This policy is simulated by setting the beer legal drinking age equal to 21 for each youth in our NHANES II sample and by setting the border age variable equal to zero. The resulting distribution shows the percentage distribution of the frequency of beer consumption that would have been observed if the legal drinking age had been 21 throughout the period of the NHANES II survey (February 1976 February 1980). Since the mean legal drinking age was 19 , the simulation gives the impact of a 10 percent increase on average in the drinking age. Three Federal excise tax policies are considered. The first indexes the Federal excise tax on a six-pack of beer, which has been fixed at $\$ .16$ in nominal terms since 1951 , to the rate of inflation since 1951 . It is termed the inflation tax policy. Under it the real price of beer in 1967 dollars faced by an NHANES II youth examine in year $t$ becomes

$$
\mathrm{p}_{\mathrm{t}}^{*}=\left[\mathrm{p}_{\mathrm{t}}-\$ .16+(\$ .16)\left(c_{\mathrm{t}, 51}\right)\right] /\left(\mathrm{c}_{\mathrm{t}, 67}\right)
$$

where $p_{t}$ is the actual money price faced by the youth, $c_{t, 51}$ is the CPI in year $t$ relative to 1951 , and $c_{t, 67}$ is the CPI in year $t$ relative to 1967 . The second tax policy raises the excise tax on a six pack of beer from $\$ .16$ to $\$ .52$ to equalize the rates at which the alcohol in beer and liquor are taxed (see note 3 ). It is termed the alcohol tax equalization policy. In this simulation the real beer price is given by 


$$
p_{t}^{\prime}=\left(p_{t}-\$ .16+\$ .52\right) /\left(c_{t, 67}\right)
$$

The third tax policy combines the first two and is termed the combined tax policy. The real beer price is given by

$$
\hat{p}_{t}=\left[p_{t}-\$ .16+(\$ .52)\left(c_{t, 51}\right)\right] /\left(c_{t, 67}\right) \text {. }
$$

The resulting simulation contains the percentage distribution of beer consumption that would have prevailed if the excise tax had been indexed to the rate of inflation since 1951 during the period of NHANES II and if the alcohol in beer had been taxed as heavily as the alcohol in liquor.

Each tax policy simulation assumes that a tax increase is fully passed on to consumers or that the beer industry is competitive and has an infinitely elastic supply curve. The inflation excise tax policy causes the price of beer to rise by approximately 12 percent in the sample period. This percentage increase in price is almost the same as the percentage increase in the legal drinking age that results when it is raised from 19 to 21. The alcohol tax equalization policy involves an 18 percent increase in price. Both policies combined amount to a substantial rise in the price of beer of 57 percent. ${ }^{25}$ Although the price of beer rises relative to the price of liquor, our demand function estimates suggest that youths would not substitute liquor for beer. Thus, cross price effects are assumed to be zero in the simulations.

Table 3 contains the results of the simulations. Two simulations of each policy are presented. The first is based on the beer demand function that excludes the religion variables, while the second is based on the beer demand function that includes the religion variables.

According to Panels $A$ and $B$ of Table 3, the number of youths who drink 
Predicted Effects of Isposicion of a Unfform Legal Drinking Age of 21 or Increase in Federal Exclse Tax on Beer on Frequency of Beer Consumption

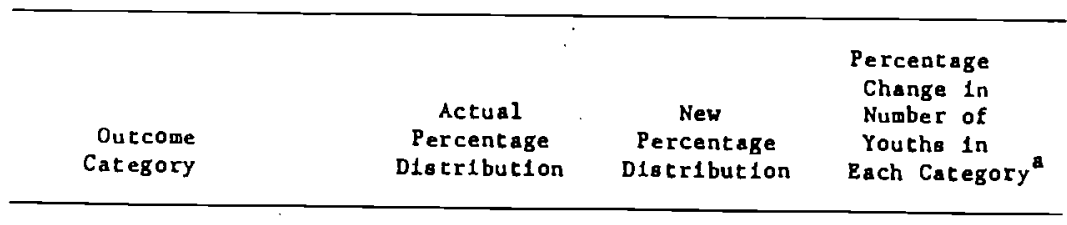

Panel A: Uniform Legal Drink1ng Age of 21, Religion Var1ables Excluded

$\begin{array}{llrr}4-7 \text { times a week } & 10.99 & 7.84 & -28.66 \\ 1-3 \text { times week } & 27.74 & 23.48 & -15.36 \\ \text { les than once a week } & 18.78 & 18.21 & -3.04 \\ \text { never } & 42.49 & 50.47 & +18.78\end{array}$

Panel B: Unfform Legal Drinking Age of 21, Rel1gion Varlables Included

$\begin{array}{llrr}4-7 \text { t1mes week } & 11.43 & 8.40 & -26.51 \\ 1-3 \text { t1mes week. } & 27.27 & 25.24 & -7.44 \\ \text { less than once week } & 18.51 & 19.96 & +7.83 \\ \text { never } & 42.78 & 46.40 & +8.46\end{array}$

Panel Ci Inflation Tax Policy, Religion Variables Excluded

$\begin{array}{llrr}4-7 \text { times week } & 10.99 & 9.83 & -10.56 \\ 1-3 \text { timeg week } & 27.74 & 26.15 & -5.73 \\ \text { less than once a week } & 18.78 & 18.81 & +.16 \\ \text { never } & 42.49 & .45 .21 & +6.40\end{array}$

Panel D: Inflation Tax Policy, Religion Varlableg Included

$\begin{array}{llll}4-7 \text { times week } & 11.43 & 10.97 & -4.02 \\ 1-3 \text { t1mes a week } & 27.27 & 26.00 & -4.66 \\ \text { les than once a week } & 18.51 & 18.06 & -2.43 \\ \text { never } & 42.78 & 44.97 & +5.12\end{array}$

Panel E: Alcohol Tax Equal1zation Pollcy, Rel1gion Variables Excluded

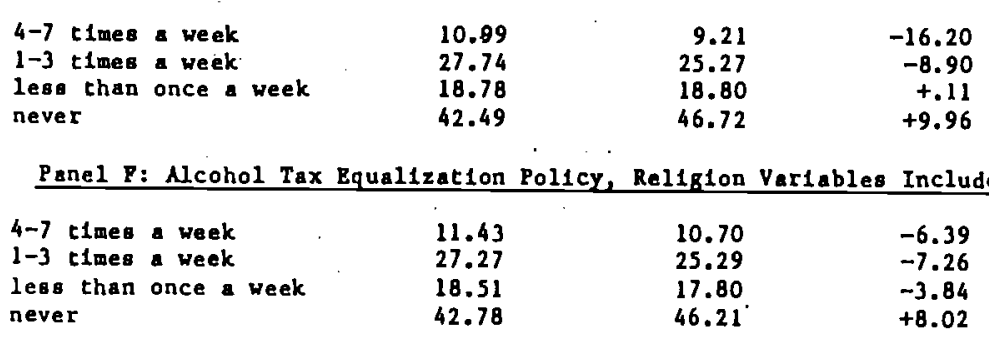

Panel G: Combined Tax Policy, Religion Variables Excluded

$\begin{array}{llrr}4-7 \text { times a week } & 10.99 & 6.15 & -44.04 \\ 1-3 \text { times a week } & 27.74 & 20.13 & -27.43 \\ \text { less than once a week } & 18.78 & 18.29 & -2.61 \\ \text { never } & 42.49 & 55.43 & +30.45\end{array}$

Panel H: Comb1ned Tax Pollcy, Religion Variables Included

$\begin{array}{llll}4-7 \text { t1mes week } & 11.43 & 9.19 & -19.60 \\ 1-3 \text { t1mes week } & 27.27 & 21.25 & -22.08 \\ \text { less than once a week } & 18.51 & 16.11 & -12.97 \\ \text { never } & 42.78 & 53.45 & +24.94\end{array}$

acolumn 1 minus column 2 divided by column 1 and multiplied by 100 . 
beer frequently ( 11 percent of all youths based on actual values of all independent variables) or fairly frequently (28 percent of all youths, which is an average of the actual percentages in Panels A and B) falls substantially in response to the enactment of a uniform legal drinking age of 21 in all states. To be precise, the number of frequent beer drinkers falls by 29 percent in Panel A and by 27 percent in Panel B. At the same time the number of fairly frequent beer drinkers falls by 15 percent in the former panel and by 7 percent in the latter panel. These declines imply increases in the number of youths who do not drink beer ( 43 percent of all youths) that range from 8 percent to 19 percent. If averages of the figures in the last columns of Panels $A$ and $B$ are taken as "best estimates," then the drinking age policy causes the number of youths who drink beer 4-7 times a week to fall by 28 percent and the number who drink beer 1-3 times a week to fall by 11 percent. Simultaneously, the number of infrequent beer drinkers rises by 2 percent and the number of nonparticipants rises by 14 percent.

Either of the two excise tax policies taken alone produces smaller declines in the number of frequent or fairly frequent beer drinkers than the drinking age policy. Based on the best estimates (averages of the figures in the last columns of Panels $C$ and $D$ ), the inflation tax policy causes the number of youths in the former category to decline by 8 percent and the number of youths in the latter category to fall by 6 percent. The corresponding reductions under the alcohol tax equalization policy are 11 percent and 8 percent (see Panels $E$ and F). These results suggest that a 10 percent increase in the drinking age has a larger impact on the frequency of beer consumption by youths than a 12 or 18 percent increase in 
the real price of beer.

Under the combined tax policy, the incidence of excessive drinking falls dramatically (see Panels $G$ and $H$ ). To be specific, the number of youths who drink beer 4-7 times a week, 1-3 times a week, and less than once a week fall by 32 percent, 24 percent, and 8 percent, respectively. 26 Simultaneously, the number of youths who do not drink beer rises by 28 percent.

Although the combined tax policy has somewhat larger effects on the rates of frequent and fairly frequent beer consumption than the drinking age policy, it probably is more notable that both policies have sizable negative impacts on these measures of beer consumption. Put differently, the negative responses are not limited to the probability of infrequent drinking. Indeed, that probability rises under the drinking age policy. It falls under the tax policy but by a smaller percentage amount than the other two probabilities. Even the absolute reduction in the infrequent drinking rate ( 1 percentage point on average) is smaller than the absolute reductions in the fairly frequent and frequent rates ( 7 percentage points and 4 percentage points, respectively).

To summarize, our results suggest that the frequency of the consumption of beer, the most popular alcoholic beverage among youths, is inversely related to the real price of beer and to the minimum legal age for its purchase and consumption. The negative price and legal drinking age effects are by no means limited to reductions in the fraction of youths who consume beer infrequently (less than once a week). Instead, the fractions of youths who consume beer fairly frequently (1-3 times a week) and frequently (4-7 times a week) fall more in absolute or percentage terms than 
the fraction of infrequent drinkers when price or the drinking age rises. These are striking findings because frequent and fairly frequent drinkers are likely to be responsible for a large percentage of youth motor vehicle accidents and deaths.

With regard to the magnitudes of the effects at issue, a Federal policy that simultaneously taxes the alcohol in beer and liquor at the same rates and offsets the erosion in the real beer tax since 1951 would have reduced the number of youths who drink beer frequently (approximately 11 percent of all youths) by 32 percent during the period of NHANES II and would have reduced the number of fairly frequent beer drinkers (approximately 28 percent of a11 youths) by 24 percent. The enactment of a minimum uniform drinking age of 21 in all states would have reduced the number of frequent drinkers by 28 percent and the number of fairly frequent drinkers by 11 percent. These figures suggest that, if reductions in youth alcohol use and abuse are desired, both a uniform drinking age of 21 and an increase in the Federal excise tax rate on beer are effective policies to accomplish this goal. 27 They also suggest that the tax policy may be more potent than the drinking age policy.

It does not follow that we have provided enough evidence to justify the approximately eight fold (thirteen fold based on the 1984 CPI) increase in the Federal excise tax on beer that serves as the basis of the above computations. Excise tax hikes impose welfare costs on all segments of the population, while a drinking age policy is targeted at the group in the population that accounts for a disproportionate share of motor vehicle accidents and deaths. On the other hand, the enforcement and administrative costs associated with a uniform minimum drinking age of 21 may exceed 
those associated with the tax policy. Moreover, an excise tax increase may reduce excessive alcohol consumption by adults as we11 as by youths. Finally, Becker (1968) has shown that the optimal way for a society to deter offenses is via a system of monetary fines. Of course, youthful drunken drivers may respond to an increase in the fine for this offense only if the probabilities of apprehension and conviction are nontrivial. If substantial resources must be allocated to raising these probabilities, the excise tax policy may be preferable to or complementary with a system of large fines. In conclusion more research is required to formulate the best mix of policies to deal with youth alcohol abuse. Our study represents a useful first step in this process. 


\section{FOOTNOTES}

${ }^{*}$ Research for this paper was supported by Grant Number 5 R01 AA05849 from the National Institute on Alcohol Abuse and Alcoholism to the National Bureau of Economic Research. We are Indebted to Gary Marshall for providing us with data on the price of Seagram's 7-Crown and to Stanley Ornstein for providing us with data on the price of a leading brand of beer. We wish to thank Gary Becker, Ph1l1p Cook, Michael Jacobson, Patrick King, Kevin Murphy, and Stanley Ornstein for helpful comments. We also wish to thank Frank Chaloupka and Eml1 Berendt for research assistance. This paper has not undergone the review accorded of flctal NBER publications; In particular, it has not been submitted for approval by the Board of Directors.

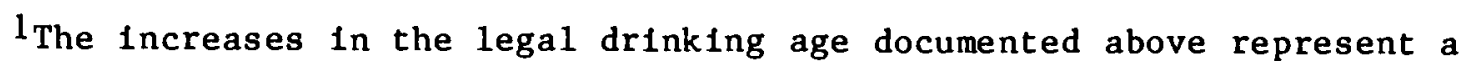
dramatic reversal of the downward trend between 1970 and 1975 . In that period, 29 states lowered their drinking age to conform with a Federal shift in the voting age from 21 to 18 in 1970.

2 The Federal excise tax rate on distilled spirits was raised from $\$ 10.50$ per proof gallon to $\$ 12.50$ effective October 1,1985 , as part of the Deficit Reduction Act of 1984 .

${ }^{3}$ Under an ad valorem alcoholic beverage exclse tax system, the tax rate would be set at a fixed proportion of wholesale price.

${ }^{4}$ Under the Federal excise tax on 11quor of $\$ 10.50$ per gallon of liquor ( 50 percent alcohol by volume) in effect prior to October 1, 1985, one gallon of alcohol in 11quor was taxed at a rate of $\$ 21$. Since the Federal excise tax on beer 1 s $\$ .29$ per gallon and since one gallon of beer contalns 


$$
\text { F }-2
$$

4.5 percent alcohol by volume, the tax rate on one gallon of alcohol in beer is $\$ 6.44$. The alcohol on liquor is taxed fifteen times as heavily as the alcohol in wine, and the proposals mentioned above also contain provisions to correct this distortion.

${ }^{5}$ At least two states -- Texas and Kansas -- have adopted laws that will revoke the 21 drinking age as soon as the legislation expires (Insurance Institute for Highway Safety 1985).

${ }^{6}$ Maisto and Rachal (1980) have studied the effects of differences in legal drinking ages among states on teenage alcohol use in a 1978 national drinking survey. Their research is limited to youths who are almost all below the lowest legal drinking age of 18 and is conducted in a univariate context.

${ }^{7}$ In a penetrating economic analysis of rational addiction over the life cycle, Becker and Murphy (1985) show that the impact of habit formation or peer pressure on price responsiveness depends upon whether the price variation is permanent or temporary, whether the magnitude of the effect is measured by the slope or the elasticity, and whether the outcome pertains to the probability of consuming the addictive good or to consumption given participation. In certain cases adults can be more responsive to price than youths in their model, while in other cases the reverse holds.

${ }^{8}$ NHANES II is described in detail by NCHS (1981).

${ }^{9}$ of the variables employed in the demand functions, the only ones with missing values are alcohol use and family income. In each case the number of observations with missing values is very small.

${ }^{10}$ The actual beverage-specific frequency measure in NHANES II has more 
categories than those given in Table 1. The complete set of outcomes is never, less than once a week, 1-6 times a week (each of the 6 outcomes can be reported), and 1-24 times a day (each of the 24 outcomes can be reported). We collapse these 32 outcomes into 4 because, as Indicated In the text, the number of drinks consumed per drinking occasion is 1ikely to rise as the number of occastons rises and because very frequent consumers are likely to underreport. In addition, it is possible that respondents in the 1-24 times a day categories drink every day and are indicating the number of drinks consumed per day or on a typical drinking day. For these reasons, we do not form a separate category of 7 or more times a week. We have experimented with several alternative categorical variables and have found that the demand function estimates are similar to those presented in Section III.

$11^{1}$ These measures include the per capita number of establishments that are licensed to sell alcoholic beverages, a dichotomous variable that ind1cates whether off-premise alcoholic beverage stores are state owned and operated, a dichotomous variable that indicates whether drug and grocery stores can sell alcoholfc beverages, and a dichotomous variable that indicates whether blllboard advertising of alcohollc beverages is allowed. All of them pertain to the state in which a given youth resides. Arluck's results are based on ordinary least squares regressions. It is beneficial for us to limit the set of Independent variables because the estimation techniques that we employ (see Section III.D) are computer intensive.

${ }^{12}$ In the case of beer, a few states have two legal drinking ages. One age is for beer that contains 3.2 percent or less alcohol by weight, and 
the second and higher age is for beer that contains more than 3.2 percent alcohol by weight. We use the former variable, but it is very highly correlated with the latter. The beer and liquor legal drinking ages also are highly correlated (the latter always is greater than or equal to the former) and cannot be included in the same demand equation. If beer and 1iquor were substitutes, an increase in the liquor legal drinking age should increase the demand for beer. Studies summarized by Ornstein (1980), however, find almost no substitution among alcoholic beverages. Additional evidence on this lack of substitution is reported in Section III.

${ }^{13}$ This statement also pertains to the border legal drinking age variable described below. Minnesota raised its legal drinking age from 18 to 19 effective September 1, 1976. The legislation contained a grandfather clause that exempted youths who were 18 years of age as of August 31,1976 from the new act. This clause is taken into account in our legal drinking age variables for Minnesota youths.

${ }^{14}$ Since the youth's age is included as an independent variable, the specification employed here is equivalent to one in which alcohol use $(y)$ depends on the youth's age (a), the difference between the legal drinking age and age $\left(x_{1}=d-a\right)$, and a vector of additional variables $\left(x_{2}\right)$

$$
\mathrm{y}=\alpha_{0}+\alpha_{1} \mathrm{a}+\alpha_{2} \mathrm{x}_{1}+\alpha_{3} \mathrm{x}_{2}
$$

Substitute the definition of $x_{1}$ into the above equation to obtain

$$
y=\alpha_{0}+\left(\alpha_{1}-\alpha_{2}\right) a+\alpha_{2} d+\alpha_{3} x_{2}
$$

Note that the coefficient of $x_{1}$ in the first equation is identical to the coefficient of $d$ in the second equation. 
${ }^{15}$ Specifically, let $t$ be a time counter that starts at 0 in January 1979 and ends at 12 in January 1980, and let $p_{j t}$ be the price of beer in the $j^{\text {th }}$ state in month $t$. Then

$$
p_{j t}=p_{j 0}+b t,
$$

where $b$ is the monthly time trend from the regression. The regression employs annual price data, with the price in 1976, for example, defined as an average of the prices in January 1976, July 1976, and January 1977. Annual data are used because state excise tax rates on beer are very stable over time. Moreover, when a state raises its tax rate, beer prices may rise gradually rather than instantaneously. Indeed, the increase may begin before the actual date on which the tax rate is scheduled to rise. The regression is estimated for a cross section of the contiguous states of the U.S. for the years 1976, 1977, and 1978. Each observation is weighted by the square root of the population of the state in a given year. The annual trend obtained from the regression is converted to a monthly trend by dividing it by 12 .

${ }^{16}$ The earliest NHANES II examination was conducted on February 20, 1976 and the latest was conducted on February 27, 1980. Therefore the mid-month dates are January 1976 through January 1980.

${ }^{17}$ Although we have specified real income-real price demand functions, we interpret the estimated price effects as uncompensated (money incomeconstant) rather than compensated (utility-constant) substitution effects. One consideration is that family income may be a very imperfect measure of a youth's command of real resources. A second consideration is that the CPI measures the cost of living of a 4-person family. Expenditure patterns 
and thus the cost-of-living index of that unit are likely to be very different from those of a youth between the ages of 16 and 21 . For the same reason, seasonal patterns in a youth's cost-of-living index may be very different from seasonal patterns in the CPI. Consequent1y, we do not deflate the monthly beer price by the monthly CPI. In preliminary research we estimated demand functions with money family income, the money price of beer, and a monthly time trend (a proxy for the youth's CPI) as regressors. The price effects in this specification were very similar to those reported in Section III).

${ }^{18}$ The seven additional brands are 01d Crow (bourbon), 01d Grand-Dad (bonded whiskey), Dewar's (scotch), Smirnoff (vodka), Bacardi (rum), Canadian Club (whiskey), and Beefeater (gin). The prices of the eight brands all are highly correlated in a positive direction. In a time series of state cross sections for the period of NHANES II, the lowest pairwise correlation coefficient is $\mathbf{. 7 3}$. The correlation coefficient between the price of Seagram's 7-Crown and an unweighted average of the prices of the eight brands is .94. Recently, sales of Bacardi and Smirnoff have overtaken sales of Seagram's 7-Crown. In this context note that the correlation coefficients between the price of Seagram's 7-Crown and the prices of Bacardi and Smirnoff are .92 and .93 , respectively.

${ }^{19}$ Similar comments can be made with respect to drinking age effects that do not control for drinking sentiment. Although it might appear as if the drinking age effect is overstated, this need not be the case. For example, the high youth motor vehicle accident mortality rate in a state where prodrinking sentiment is widespread may result in the enactment of a high 
legal drinking age.

$$
\begin{gathered}
20 \text { Since } \sum_{k=1}^{4} \pi_{1 k}=1, \\
\pi_{14}=\left[1+\sum_{k=1}^{3} \exp \left(\alpha_{k}+\sum_{t=1}^{n} \beta_{k t} x_{1 t}\right)\right]^{-1},
\end{gathered}
$$

and

$$
\left(\partial \pi_{14} / \partial x_{1 t}\right)=-\sum_{k=1}^{3}\left(\partial \pi_{1 k} / \partial x_{1 t}\right) .
$$

$21_{\text {An }}$ estimation issue in addition to those discussed above arises because NHANES II is a stratifled cluster sample rather than a simple random sample. Consider an ordinary least squares regression in this context. If the regression is fit under the assumption of simple random sampling, regression coefficlents are unblased, but their t-ratios are overstated (Holt 1977). A computer program called SURREGR, described by Holt (1977), estimates unblased t-ratios for ordinary least squares regressions - $t$ ratios that account for sample design effects. There 1s, however, no SURREGR equivalent of a logit model. This suggests that the asymptotic tratios (the ratios of logit coefficlents to their standard errors) shown in Section III may be blased upward. There is, however, a factor that goes in the opposite direction. We employ a relatively sparse set of regressors; standard errors would fall if this set were expanded. Recall that Arluck (In progress) finds that the coefficients of interest in the demand functions are not sensitive to the inclusion of additional independent variables.

22 The ratios of logit coefficients to their standard errors do not have Student's $t$ distribution. These ratios do, however, have an asymptotic 
normal distribution. Therefore, the $t$ test is an asymptotic one.

${ }^{23}$ Statements concerning statistical significance in the text are based on one-tailed tests except when the direction of the effect is unclear on a priori grounds or when the estimated effect has the "wrong sign." In the latter cases two-tailed tests are used. In particular, the own price and legal drinking effects are expected to be negative, and the border legal age effects are expected to be positive. When no significance level is indicated, it is assumed to be 5 percent for a one-tailed test.

${ }^{24}$ Based on equation (13), the elasticity of $\pi_{1 k}$ with respect to $x_{1 t}$ is

$$
\varepsilon_{i k t}=\left(\beta_{k t}-\sum_{k=1}^{3} \pi_{i k} \beta_{k t}\right) x_{1 t} .
$$

This elasticity is computed for each youth in the sample by first predicting $\pi_{1 k}$ from equation (1) and the second equation in note 20 . The resulting figures are averaged over all youths to obtain the elasticity reported in the text. Note that, since each of the three logit coefficients of price is negative, the marginal price effect [see equation (3)] and the elasticity will be negative if

$$
\left|\beta_{k t}\right|>\left|\sum_{k=1}^{3} \pi_{i k} \beta_{k t}\right|
$$

Clearly, the above inequality must hold with respect to the largest $\beta_{k t}$. Given the range of the estimated $\pi_{i k}$ and the values of $\beta_{k t}$ in our sample, the inequality also is satisfied with respect to the second-1argest logit coefficient of price in a majority of cases.

${ }^{25}$ The percentage increases in price pertain to the actual mean price of beer in the NHANES II sample ( $\$ 1.03$ per six-pack in 1967 dollars) compared 
to the new mean price under each of the three tax policies. Since the excise tax and legal drinking age increases are non marginal and the logit functions are nonlinear, the simulations are employed to evaluate their effects. This is preferable to computing marginal price or legal drinking age effects at the point of means or for each individual and then multiplying by the change in the policy variable at issue. Note that the actual percentage distribution of the frequency beer consumption in Table 3 differs from the corresponding "observed" distribution in Table 1. The latter contains, for example, the mean of a dichotomous variable that equals one if a youth is a frequent beer drinker. These differences emerge because a multinomial logit equation, unlike a multiple regression, does not necessarily pass through the point of means of the sample. But they are very small. In particular, the difference between an outcome probability in Table 1 and the corresponding probability in Table 3 is always less than 1 percentage point in absolute value.

26 Although the elasticity of the probability of infrequent beer consumption with respect to the real price of beer is positive, the probabi1ity of infrequent beer drinking falls as the excise tax rises. This is because the probability of infrequent drinking is not a monotonically increasing function of price [see equation (3)].

27 Some caution should be exercised in applying the results of the drinking age simulation to the Federal Uniform Drinking Age Act because the mean legal drinking age was closer to 20 in July 1984 than to the NHANES II mean of 19. On the other hand, as pointed out in Section I, a long-term prohibition of purchases of alcoholic beverages by persons below the age of 
21 is not a fait accompli because the penalties imposed on states that do not raise their drinking age to 21 by the Federal Uniform Drinking Age Act expire at the end of fiscal 1988. Therefore, the figures given above probably are reasonable to use in a long-term evaluation of the drinking age policy. 


\section{REFERENCES}

Arluck, G. M. "Economlc and Other Factors In Youth Alcohol Use." Ph.D. dissertation, C1ty Un1vers1ty of New York Graduate School. In progress.

Becker, G. S. "Crime and Punishment: An Economlc Approach." Journal of Pollt1cal Economy, 76, No. 2 (March/Apr1l 1968).

Becker, G. S. "Don't Ra1se the Drinking Age, Ralse Taxes." Business Week, November 25, 1985.

Becker, G. S., and Murphy, K. M. "A Theory of Rational Addiction."

Work1ng Paper, Department of Economics, Un1vers1ty of Ch1cago, April 1985.

Blane, H. T., and Hewltt, L. E. "Alcohol and Youth: An Analysis of the Literature, 1960-1975." Prepared for the National Institute on Alcohol Abuse and Alcoholism. Springfleld, V1rginia: U.S. National Technical Information Service, 1977.

Bureau of Labor Statistics, U.S. Department of Labor. Monthly Labor Review, various 1ssues.

Cook, P. J. "The Effect of L1quor Taxes on Drinking, Clrrhosis, and Auto Fatal1t1es." In Alcohol and Public Pollcy: Beyond the Shadow of Prohibition, edited by M. H. Moore and D. R. Gerstein. Washington, D.C.: National Academy Press, 1981.

Cook, P. J. "Increasing the Federal Alcohol Exclse Tax." In Toward the Prevention of Alcohol Problems: Government, Business, and Community Action, edited by D. R. Gerstein. Washington, D.C.: National Academy Press, 1984. Cook, P. J., and Tauchen, G. "The Effect of Liquor Taxes on Heavy Drinking." Bell Journal of Economics, 13, No. 2 (Autumn 1982). 
Cook, P. J., and Tauchen, G. "The Effects of Minimum Drinking Age Legisslation on Youthful Auto Fatalities, 1970-1977." Journal of Legal Studies, 13, No. 1 (January 1984).

Distilled Spirits Council of the United States. "Price per Fifth for Selected Types and Brands of Liquor in Control and License States." Various years.

Gordon, T., and Kanne1, W. B. "Drinking and Its Relation to Smoking, BP, Blood Lipids, and Uric Acid." Archives of Internal Medicine, 143 (1983).

Grossman, M.; Coate, D.; and Arluck, G. M. "Price Sensitivity of Alcoholic Beverages in the United States." In Control Issues in Alcohol Abuse Prevention: Strategies for Communities, edited by H. D. Holder. Greenwich, Connecticut: JAI Press, Inc., forthcoming.

Harris, J. E. "More Data on Tax Policy." In Toward the Prevention of Alcohol Problems: Government, Business, and Community Action, edited by D. R. Gerstein. Washington, D. C.: National Academy Press, 1984.

Holt, M. M. "SURREGR: Standard Errors of Regression Coefficients from Sample Survey Data." Raleigh, North Carolina: Research Triangle Institute, 1977 .

Insurance Institute for Highway Safety. The Highway Loss Reduction Status Report, 20, No. 9 (August 10, 1985). Jacobson, M., and Albion, M. "Raising Alcohol Taxes Is the Way to Cut Drinking and the Debt." Washington Post, August 11, 1985. Leibenstein, H. "Bandwagon, Snob, and Veblen Effects in the Theory of Consumer Demand." Quarterly Journal of Economics, 64, No. 1 (May 1950). 
Lewit, E. M.; Coate, D.; and Grossman, M. "The Effects of Government Regulation on Teenage Smoking." Journal of Law and Economics, 24, No. 3 (December 1981).

Luks, A. Will America Sober Up? Boston: Beacon Press, 1983. Maddala, G. S. Limited-Dependent and Qualitative Variables in Econometrics. Cambridge, England: Cambridge University Press, 1983. Maisto, S. A., and Rachal, J. V. "Indications of the Relationship among Adolescent Drinking Practices, Related Behaviors, and Drinking-Age Laws." In Minimum-Drinking-Age Laws: An Evaluation, edited by H. Wechsler. Lexington, Massachusetts: D.C. Heath and Company, 1980. McFadden, D. "Conditional Logit Analys is of Qualitative Cholce Behavior." In Frontiers of Econometrics, edited by P. Zarembka. New York: Academic Press, 1973.

Midantk, L. "The Validity of Self-Reported Alcohol Consumption and Alcohol Problems: A Literature Review." British Journal of Addiction, 77 (1982).

Moore, M. H., and Gerstein, D. R., editors. Alcohol and Public Policy: Beyond the Shadow of Prohibition. Washington, D. C.: National Academy Press, 1981 .

National Center for Health Statistics. Plan and Operation of the Second Health and Nutrition Examination Survey, 1976-1980. U.S. Department of Health and Human Services, Vital and Health Statistics, DHHS Publication No. (PHS) 81-1317, Series 1, No. 15, 1981. National Highway Traffic Safety Administration, U.S. Department of Transportation. Fatal Accident Reporting System 1981. DOT HS 806 251, January 1983.

Ornstein, S. I. "Control of Alcohol Consumption Through Price Increases." Journal of Studies on Alcohol, 41, No. 9 (1980). 


$$
R-4
$$

Ornstein, S. I., and Hanssens, D. M. "Alcohol Control Laws and the Consumption of Distilled Spirits and Beer." Journal of Consumer Research, 12 (September 1985).

Polich, J. M. "The Validity of Self-Reports in Alcoholism Research." Addictive Behaviors, 7 (1982).

Quinn, B., et al. Churches and Church Membership in the United States, 1980. Atlanta, Georgia: Glenmary Research Center, 1982.

Rachal, J. V., et a1. "The Extent and Nature of Adolescent Alcohol and Drug Use: The 1974 and 1978 National Sample Survey." Prepared for National Institute on Alcohol Abuse and Alcoholism. Springfield, Virginia: U.S. National Technical Information Service, 1980. Smart, R. G., and Goodstadt, M. S. "Effects of Reducing the Legal Alcohol-Purchasing Age on Drinking and Drinking Problems: A Review of Empirical Studies." Journal of Studies on Alcohol, 38, No. 7 (1977).

Voas, R. B., and Moulden, J. "Historical Trends in Alcohol Use and Driving by Young Americans." In Minimum-Drinking-Age Laws: An Evaluation, edited by H. Wechsler. Lexington, Massachusetts: D.C. Heath and Company, 1980.

Wagenaar, A. C. Alcoho1, Young Drivers, and Traffic Accidents. Lexington, Massachusetts: Lexington Books, 1983. Wagenaar, A. C. "Legal Minimum Drinking Age Changes in the United States: 1970-1981." Alcohol Health and Research World (Winter 1981/82). Williams, R., and Gillies, P. "Do We Need Objective Measures to Validate Self-reported Smoking?" Public Health London, 98 (1984). 


$$
R-5
$$

Williams, T. P., and Lillis, R. P. "Changes in Alcohol Consumption by Eighteen Year 01ds Following an Increase in New York State's Purchasing Age to Nineteen." Presented at the National Council on Alcoholism, National Alcoholism Forum, Washington, D. C., April 1985. 